\title{
Commentary on the Heat Transfer Mechanisms Controlling Propagation in Nanothermites
}

\author{
Garth C. Egan and Michael R. Zachariah* \\ Department of Chemical and Biomolecular Engineering and Department of Chemistry and \\ Biochemistry, University of Maryland, College Park, MD 20742, USA \\ *Corresponding Author. E-mail address: mrz@umd.edu
}

\begin{abstract}
The combustion of nanothermites is a complex multiphase process that is still not well understood. One important aspect that is in need of further examination is the heat transfer mechanisms that drive combustion. Here we present some simple calculations to critically analyze the viability of conduction, convection, and radiation mechanisms of heat transfer as it relates to reaction propagation in nanothermites. While convection has generally been accepted as the critical mechanism for heat transfer, we show that the movement of hot gases cannot account for the required energy flow. Instead, it is illustrated that the movement of condensed phase material plays the critical role in heat transfer and should be accounted for in future models.
\end{abstract}

\section{Introduction}

Despite the over two decades of research into aluminum based nanoenergetics, there is still much that is unknown about the underlying physics that control the propagation of reaction. In particular, for nanothermites, or metastable intermolecular composites (MICs), made from well mixed fuel and oxidizer nanoparticles there are a wide range of theories to explain the reaction process [1-4]. However, one point of general agreement has been that convection is the dominant form of heat transfer during combustion at low densities. This has been supported by experimental results which have shown that flame speeds are maximized with confinement, high gas production, low packing densities and low initial pressures [5-10]. Several studies have investigated the issue directly and concluded that it is a convective process, rather than conduction or radiation, that is responsible for the high flame speeds observed [5,10]. Generally it follows from these results that the hot gases are responsible for transporting the heat during 
combustion. However, recent results have shown that the movement of condensed phase (i.e., solid or molten) material is significant in these systems and could play a role in transferring energy and propagating the reaction [11-13].

Here we present a series of simple calculations to determine the viability of the various possible energy delivery mechanisms. From this simple base, we conclude that movement of hot condensed matter, is likely the primary mode of heat transfer responsible for thermite propagation.

\section{Calculation}

\subsection{Calculation Parameters}

To make this process as simple as possible, all the calculation parameters are derived from an $\mathrm{Al} / \mathrm{CuO}$ burn tube experiment, which involves loosely packed material in a large length/diameter ratio tube $[5,9,10,14]$. When ignited, the pressure and/or luminous front can be observed as it propagates forward through unreacted material. For our calculation we assume a tube with $3.2 \mathrm{~mm}$ inner diameter and packed to $6 \%$ theoretical maximum density of $\mathrm{Al} / \mathrm{CuO}$ mixed to an equivalence ratio of 1 [9]. To account for the oxide shell, the aluminum nanoparticles are assumed to be $70 \%$ active by mass. Therefore the reactant mixture is $17.1 \% \mathrm{Al}$, $75.6 \% \mathrm{CuO}$, and $7.3 \% \mathrm{Al}_{2} \mathrm{O}_{3}$ by mass, and there is $2.4 \mathrm{mg}$ of this mixture for every linear millimeter of packed tube.

\begin{tabular}{cccccc}
\hline $\begin{array}{c}\text { Material } \\
\text { system }\end{array}$ & $\begin{array}{c}\text { Tube inner } \\
\text { diameter }\end{array}$ & $\begin{array}{c}\text { Packing } \\
\text { density }\end{array}$ & $\begin{array}{c}\text { Assumed ignition } \\
\text { temperature }\end{array}$ & $\begin{array}{c}\text { Mass per } \\
\text { unit length } \\
\text { of tube }\end{array}$ & $\begin{array}{c}\text { Energy needed for } \\
\text { reactants to reach } \\
\text { ignition temperature }\end{array}$ \\
\hline Al/CuO & $\mathbf{3 . 2} \mathbf{~ m m}$ & $\mathbf{6 \%} \mathbf{T M D}$ & $\mathbf{1 0 5 0 ~ K}$ & $2.4 \mathrm{mg} / \mathrm{mm}$ & $1.5 \mathrm{~J} / \mathrm{mm}$ \\
\hline
\end{tabular}

Table 1- Parameters used in the calculations and estimations made in this section. Values in bold were chosen based on the experiments in References [5,15]. The other values were calculated based on those parameters.

In order for reaction to propagate, the cold and unreacted material must be heated to the point of self-sustaining reaction (i.e., ignition). For simplicity we assume no exothermic selfheating occurs prior to this point, which is reasonable given the short times scales involved in the overall combustion process [2]. We also assume that ignition occurs at $1050 \mathrm{~K}$ as found in high heating rate $\left(\sim 10^{5} \mathrm{~K} / \mathrm{s}\right)$ experiments [15]. Based on the data in the NIST WebBook, the energy 
needed to raise the temperature of the reactants from $300 \mathrm{~K}$ to the ignition temperature is $1.5 \mathrm{~J}$ per linear mm of packed tube [16]. All of the values discussed so far can be found summarized in Table 1. From this base of values, we can make estimates on the timescales and heating rates that can be achieved with the different mechanisms of heat transfer.

\subsection{Conduction}

We first address conduction based on an upper bound estimate of fully dense aluminum, which has a thermal conductivity of $237 \mathrm{~W} / \mathrm{mK}$ [17]. From experimental measurements of pressure rise times and flame speeds, the reaction front thickness in a burn tube has been calculated to be $10 \mathrm{~mm}$ thick, which lines up reasonably well with values of 10-40 $\mathrm{mm}$ measured from temperature rises observed in pyrometry experiments $[5,14,18]$. From this, we estimate a thermal gradient of $2.7 \times 10^{5} \mathrm{~K} / \mathrm{m}$ based on a temperature drop from $3000 \mathrm{~K}$ to $300 \mathrm{~K}$ over this distance. Fourier's law then gives a heat flux of $6.4 \times 10^{7} \mathrm{~W} / \mathrm{m}^{2}$, which when multiplied times the cross-sectional area of the tube gives $515 \mathrm{~W}$. The maximum flame speed that could be achieved by this heat transfer can then be calculated by dividing that heat flow by the energy needed to reach ignition per unit length to give $0.34 \mathrm{~m} / \mathrm{s}$. This is orders of magnitude slower than the burn speeds typically observed in burn tubes $(>500 \mathrm{~m} / \mathrm{s})$, and significantly slower than even those found for open configuration experiments $(>5 \mathrm{~m} / \mathrm{s})[9,12]$. Additionally, consider that we assumed fully dense $\mathrm{Al}$ for conduction when, in reality, the porous nanoparticle beds found in these experiments have effective thermal conductivities an order of magnitude lower than bulk $[19,20]$. Additionally, inclusion of $\mathrm{CuO}$, which has an order of magnitude lower thermal conductivity than $\mathrm{Al}$, would have a similar detrimental effect. For a one order of magnitude drop in conductivity from bulk Al, a reaction velocity of $10 \mathrm{~m} / \mathrm{s}$, maintained by conduction alone, requires a reaction zone length (temperature drop distance) of just $\sim 30 \mu \mathrm{m}$, rather than the $\sim 10$

$\mathrm{mm}$ observed in experiments. Therefore in the combustion of these materials, conduction cannot account for the observed flame speeds.

\subsection{Radiation}

For radiation, we again greatly simplify the system in order to find an upper bound for heat flow. While nanoparticles have high specific surface area, during combustion they are surrounded by many equally hot particles. So for heat transport, the only radiation that will matter is that which travels forward into unreacted material. Therefore we can reduce the 
problem to just two cylinders of material with radiation passing through the presenting ends. If we assume black bodies with one hot $(3000 \mathrm{~K})$ and the other cold $(300 \mathrm{~K})$, then the heat flow can be calculated from the Stefan-Boltzmann law as $\dot{\boldsymbol{Q}}_{\text {rad }}=\boldsymbol{\sigma} \boldsymbol{A}\left(\boldsymbol{T}_{\mathbf{1}}^{\mathbf{4}}-\boldsymbol{T}_{2}^{\mathbf{4}}\right)$ where $\sigma$ is the StefanBoltzmann constant and $A$ is the cross-sectional area of the tube. This yields a radiative heat flow of just $37 \mathrm{~W}$, which is an order of magnitude less than what was found for conduction and implies an even slower flame speed. Again, this is an upper bound, since in practice the local temperature difference would be less extreme.

\subsection{Convection of Gases}

In the previous two sections we used timescale arguments to rule out conduction and radiation. For the remaining sections we will focus on the amount of energy transferred by moving material from a hot region to an equal volume cold region. Equilibrium calculations have shown that the $\mathrm{Al} / \mathrm{CuO}$ nanothermite reaction can produce $\sim 4 \mathrm{~mol} / \mathrm{kg}$ of gas, which is $>95 \% \mathrm{Cu}$ vapor [9]. This corresponds to $9.6 \times 10^{-6} \mathrm{~mol}$ in a $1 \mathrm{~mm}$ long section of burn tube. Now if we assume that this gas is moved forward from the hot reacted zone to a cold unreacted zone, it transfers heat in equilibrating with the new zone and cooling down. Here we will neglect condensation, which will be addressed separately below, and use the constant pressure heat capacity of $\mathrm{Cu}$ vapor from the JANAF tables. The constant volume heat capacity may be more relevant, but $\mathrm{C}_{\mathrm{p}}$ is higher than $\mathrm{C}_{\mathrm{v}}$ and we want an upper bound estimate. Based on these assumptions, the process of cooling $3000 \mathrm{~K} \mathrm{Cu}$ vapor to the $1050 \mathrm{~K}$ ignition point, liberates 0.4 $\mathrm{J} / \mathrm{mm}$ which is only $27 \%$ of the $1.5 \mathrm{~J}$ needed for an equal volume of reactants to reach the ignition temperature.

It has also been suggested that, rather than $\mathrm{Cu}$ vapor, intermediate species $\left(\mathrm{O}_{2}\right.$ primarily $)$ could drive the initial pressurization observed during combustion [21-24]. As diatomic gas molecules have higher heat capacities, this point is worth considering. As these species are nonequilibrium, we use results of $\mathrm{Al} / \mathrm{CuO}$ burn tube experiments that have observed pressures of 1900 PSI (130 atm) and temperatures of 3000 K [9,14]. Therefore based on our assumed tube diameter, a $1 \mathrm{~mm}$ section at those conditions will contain $4.2 \times 10^{-6} \mathrm{~mol}$ of gas based on the ideal gas law. Assuming this gas is entirely $\mathrm{O}_{2}$, cooling it in the manner discussed above liberates only $0.3 \mathrm{~J} / \mathrm{mm}$, or $20 \%$ of the ignition threshold energy, and less than that generated assuming equilibrium conditions. Based on these results, it is not accurate to model heat transfer as 
nanoparticles sitting in a hot gas, since the gases produced do not have enough thermal mass to make this process feasible.

As mentioned above, another process that must be considered in the transport and cooling of gases is that they typically contain a significant portion of condensable metal vapor. Returning to the equilibrium calculations, the $\sim 4$ mol of copper gas per $\mathrm{kg}$ of reactant produced at constant pressure (1 atm) will liberate heat when condensed [9]. Using the heat of condensation of copper gas ( $300 \mathrm{~kJ} / \mathrm{mol})$ yields $2.9 \mathrm{~J} / \mathrm{mm}$, which is $\sim 190 \%$ of the ignition threshold energy [16]. Thus the condensation of copper could theoretically account for all the necessary heat transfer of combustion. However, there are several other factors that reduce the impact of this process and make it unlikely to be the dominant mode of energy transport.

First, the assumption of 1 atm constant pressure is erroneous because, as discussed above, pressures of 1900 PSI (130 atm) have been recorded for $\mathrm{Al} / \mathrm{CuO}$ in burn tubes. These extreme pressure waves indicate that gases are generated faster than they can dissipate, which means that constant volume calculations are likely more realistic. Under a constant volume constraint, equilibrium calculations for $\mathrm{Al} / \mathrm{CuO}$ at $6 \% \mathrm{TMD}$ give just $0.31 \mathrm{~mol}$ of copper gas per $\mathrm{kg}$ of reactant. This only liberates $0.2 \mathrm{~J} / \mathrm{mm}$, which is only $15 \%$ of the energy needed to reach ignition.

Furthermore, copper vaporization is the last step in the reaction, and it is this that limits the adiabatic flame temperature to the $\mathrm{Cu}$ boiling point $(2840 \mathrm{~K}$ at $1 \mathrm{~atm})$. Therefore, the equilibrium concentration of copper vapor will only exist when the reaction is $100 \%$ complete. So for this gas to participate in heat transfer, reaction must occur significantly faster than the heat transfer. However, this does not seem to be the case as material in extended burn tubes has been found to burn for $\sim 3 \mathrm{~ms}$ [13]. In comparison, flame speeds have been found to be $>500 \mathrm{~m} / \mathrm{s}$ in burn tubes and $>5 \mathrm{~m} / \mathrm{s}$ in open configurations [9,12]. If we assume a $10 \mathrm{~mm}$ reaction zone, this corresponds to propagation timescales of $20 \mu \mathrm{s}$ and $2 \mathrm{~ms}$. This implies that propagation occurs much faster than, or at least on a similar timescales of reaction, which means that it is likely that a significant portion of the equilibrium concentration of copper vapor is not available to participate in heat transfer. Similar observations are part of what led to the suggestion that intermediate gaseous species could drive pressure rise as discussed above [21,22,24]. 
Finally we have assumed that $100 \%$ of the gases produced move forward into unreacted material, which is clearly not the case for open configurations for which this analysis is equally valid.

Thus we conclude that neither convention nor heat of condensation of metal vapor can account for the totality of the heat transport necessary to support combustion. While these calculations were based on $\mathrm{Al} / \mathrm{CuO}$, the impact of gases should be commensurate or even diminished for other thermites as $\mathrm{Al} / \mathrm{CuO}$ is one of the highest gas producing thermites on a mol/kg basis [25].

\subsection{Convection of Condensed Phase Species}

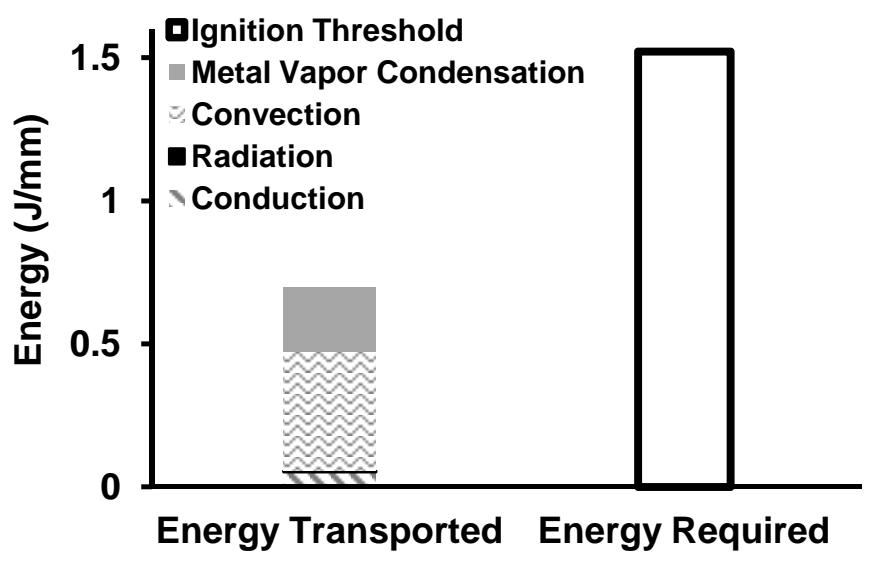

Figure 1- Estimated energy available from each form of heat transfer compared to the ignition threshold for 1 linear mm of burn tube material. Note that conduction and radiation were analyzed in terms of rates above, so the energy plotted is the amount delivered in $0.1 \mathrm{~ms}$. That corresponds to the characteristic time for $1 \mathrm{~mm}$ of material and a flame speed of $10 \mathrm{~m} / \mathrm{s}$. Higher flame speeds will correspond to shorter times and even less energy. The value shown for condensation of $\mathrm{Cu}$ is based on the amount of vapor found for a constant volume $6 \%$ TMD equilibrium calculation.

The preceding results are summarized in Figure 1, which takes the reasonable upper bound measurement for each mode of heat transfer discussed so far. For metal vapor condensation, the absolute maximum was considered implausible as discussed above, so the constant volume approximation was used instead. This figure clearly illustrates that the critical ignition threshold cannot be reached by the modes of heat transfer discussed so far. The one mechanism that remains is the movement of hot solid and molten material. Such behavior has been suggested previously. For example, with $\mathrm{Al} / \mathrm{MoO}_{3}$ it was observed that peak flame speed coincided with the highest production of gas above the melting point of Mo, which indicated that molten metal was important to propagation [11]. Additionally in open configuration, material was observed to have been thrown forward and to have ignited the unreacted material discontinuously [12]. Such behavior is not entirely surprising given the small stokes numbers of the nanoparticles will lead to significant entrainment [13]. 
To give this process a similar treatment to the previously discussed heat transfer mechanism, we examine the transport and cooling of molten $\mathrm{Cu}$ and $\mathrm{Al}_{2} \mathrm{O}_{3}$ from $3000 \mathrm{~K}$ to 1050 $\mathrm{K}$, whose solidification liberates $77 \mathrm{~kJ} / \mathrm{mol}$ and $410 \mathrm{~kJ} / \mathrm{mol}$ respectively [16]. The $2.4 \mathrm{mg} / \mathrm{mm}$ in the tube corresponds to $2.3 \times 10^{-5}$ moles of $\mathrm{Cu}$ and $7.7 \times 10^{-6}$ moles of $\mathrm{Al}_{2} \mathrm{O}_{3}$ per linear mm of burn tube. Therefore, to achieve the $1.5 \mathrm{~J} / \mathrm{mm}$ necessary for ignition, only $31 \%$ of that quantity must transported. While the transport of condensed phase material has as yet not been quantified by experiment, recent work does show that a small compact of reactants can expand $>1.5$ meters down an unfilled tube before burn out [13]. The long burn times $(\sim 3 \mathrm{~ms})$, relative to the initial expansion, observed in that experiment suggest that a mechanism involving the fast release of intermediate gaseous species causes pressure buildup and unloading that propels hot material forward, which then continues to burn. This result suggests that heat transfer involving the movement of condensed phase material offers a reasonable explanation, particularly after consideration of the other possible heat transfer mechanisms, to explain the high propagation velocities observed in nanothermites.

\section{Conclusion}

In this work we have, based on scaling arguments, ruled out conduction and radiation as significantly contributing heat transfer modes for the propagation of nanothermite combustion. We also showed that the convection of gases alone is unlikely to account for all the energy transported, even after accounting for metal vapor condensation. While these mechanisms undoubtedly contribute to combustion, these results indicate that the movement of condensed phase material will play a dominant role.

\section{Acknowledgements}

This work was supported by the Army Research Office and the Defense Threat Reduction Agency.

\section{References}

[1] S. Chowdhury, K. Sullivan, N. Piekiel, L. Zhou, M.R. Zachariah, J. Phys. Chem. C 114 (2010) 91919195.

[2] V.I. Levitas, B.W. Asay, S.F. Son, M. Pantoya, Appl. Phys. Lett. 89 (2006).

[3] V.I. Levitas, Philos. Trans. R. Soc. A 371 (2013).

[4] K.T. Sullivan, N.W. Piekiel, C. Wu, S. Chowdhury, S.T. Kelly, T.C. Hufnagel, K. Fezzaa, M.R. Zachariah, Combust. Flame 159 (2012) 2-15. 
[5] B.W. Asay, S.E. Son, J.R. Busse, D.M. Oschwald, Propellants Explos. Pyrotech. 29 (2004) 216-219.

[6] B.S. Bockmon, M.L. Pantoya, S.F. Son, B.W. Asay, J.T. Mang, J. Appl. Phys. 98 (2005).

[7] G. Dutro, S. Son, A. Tappan, The Effect of Microscale Confinement Diameter on the Combustion of an Al/MoO3 Thermite, 44th AIAA/ASME/SAE/ASEE Joint Propuls. Conf. \& Exhib., 2008.

[8] M.L. Pantoya, J.J. Granier, Propellants Explos. Pyrotech. 30 (2005) 53-62.

[9] V.E. Sanders, B.W. Asay, T.J. Foley, B.C. Tappan, A.N. Pacheco, S.F. Son, J. Propuls. Power 23 (2007) 707-714.

[10]M.R. Weismiller, J.Y. Malchi, R.A. Yetter, T.J. Foley, Proc. Combust. Inst. 32 (2009) 1895-1903.

[11]S.F. Son, B.W. Asay, T.J. Foley, R.A. Yetter, M.H. Wu, G.A. Risha, J. Propuls. Power 23 (2007) 715721.

[12]K.T. Sullivan, J.D. Kuntz, A.E. Gash, J. Appl. Phys. 112 (2012).

[13]K.T. Sullivan, O. Cervantes, J.M. Densmore, J.D. Kuntz, A.E. Gash, J.D. Molitoris, Quantifying Dynamic Processes in Reactive Materials: An Extended Burn Tube Test, Propellants Explos. Pyrotech. (2015) doi:10.1002/prep.201400267.

[14]J.M. Densmore, K.T. Sullivan, A.E. Gash, J.D. Kuntz, Propellants Explos. Pyrotech. 39 (2014) 416422.

[15]G. Jian, S. Chowdhury, K. Sullivan, M.R. Zachariah, Combust. Flame 160 (2013) 432-437.

[16]E.S. Domalski, E.D. Hearing, Condensed Phase Heat Capacity Data, in: P.J. Linstrom, W.G. Mallard (Eds.), NIST Chemistry WebBook, NIST Standard Reference Database Number 69, National Institute of Standards and Technology, Gaithersburg, MD 20899, pp. http://webbook.nist.gov, (retrieved February 4, 2015).

[17]R. Powell, C.Y. Ho, P.E. Liley, Thermal conductivity of selected materials, DTIC Document, 1966.

[18]M.R. Weismiller, J.G. Lee, R.A. Yetter, Proc. Combust. Inst. 33 (2011) 1933-1940.

[19]X.J. Hu, R. Prasher, K. Lofgreen, Appl. Phys. Lett. 91 (2007).

[20]R. Prasher, Phys. Rev. B 74 (2006).

[21]K. Sullivan, M.R. Zachariah, J. Propuls. Power 26 (2010) 467-472.

[22]A. Trebs, T.J. Foley, J. Propuls. Power 26 (2010) 772-775.

[23]L. Zhou, N. Piekiel, S. Chowdhury, M.R. Zachariah, J. Phys. Chem. C 114 (2010) 14269-14275.

[24]M.R. Weismiller, J.Y. Malchi, J.G. Lee, R.A. Yetter, T.J. Foley, Proc. Combust. Inst. 33 (2011) 19891996.

[25]S.H. Fischer, M.C. Grubelich, A Survey of Combustible Metals, Thermites, and Intermetallics for Pyrotechnic Applications, 32nd AIAA/ASME/SAE/ASEE Joint Propuls. Conf., Sandia National Laboratories, Lake Buena Vista, FL, 1996. 